\title{
The Study of 1 + X Evaluation Mode Reform
}

\author{
Tian Zhang1, Man Liu' ${ }^{2}$,iang Ji ${ }^{1}$ \\ ${ }^{1}$ Training Department, Air Force Logistics College, Xuzhou, China \\ ${ }^{2}$ Department of Basic Courses, Air Force Logistics College, Xuzhou, China \\ Email: liuman8866@163.com
}

Received 18 June 2014; revised 10 July 2014; accepted 30 July 2014

Copyright (C) 2014 by authors and Scientific Research Publishing Inc.

This work is licensed under the Creative Commons Attribution International License (CC BY).

http://creativecommons.org/licenses/by/4.0/

(c) (i) Open Access

\begin{abstract}
To solve the question of the present situation of professional education, we analyze the outstanding problems of the process, and put forward the design of content, the main measures of reform and the relationship that should be handled in the process of $1+X$ evaluation mode reform, in order to adapt to the reform of the professional education, and build a scientific and reasonable system of $1+X$ evaluation mode. Accordingly, we can improve the quality of teaching and talent training.
\end{abstract}

Keywords

Professional Education, $1+\mathrm{X}$, Evaluation Model

\section{Introduction}

In the process of professional education, examination is the important part of teaching. It not only reflects the educational idea, valuable orientation and training goal, but also is the important method to judge the teaching level and test the quality of teaching (Li, 2011; Niu, 2000; Zhao, 2010). Most important of all, along with the continuous educational reform, the teaching reform should adapt to the educational reform. We must explore and build the new mode of examination. By the reform of teaching examination we can improve the teaching quality continuously, and train highly-competent students. Consequently, it is imperative to carry out the study of examination mode on reform and build the scientific and reasonable appraisal mode.

\section{The Existed Outstanding Problem of Examination Mode in the College at Present}

For the present educational examination in recent years, the talents training in most colleges with professional education is still taking the single evaluation as the principal. Although this way of assessment is helpful for students to master the basic knowledge, but it is lack of practicality and operability, the quality of teaching and 
the cultivation of talents are affected seriously, it also becomes the disadvantages of current teaching test. The question must be resolved by reform (Dai, 2009; Han, 2011; Wu, 2011).

\subsection{The Way of Examination Is Too Easy}

According to the content and the characteristics of courses, different course has different way to exam. Now, the way of examination is too simple in a number of colleges and universities. The type of exam is machine-made, almost every examination in different classes is fill in a noun explanation, the blanks, choice, multiple-choice, calculation, short answer, discussion and so on. The way can not reflect the characteristic of course well, not to speak of testing the students on the use of the knowledge in the flexible ability. The form of exam is simple and boring, the written examination is given priority to in most of colleges and universities, but for the oral test, practical operation, pen paper examining ways is using less, so it is fail to test the ability of students comprehensively. The way of questioning is too single, this is "what is a", "why", "relate and analyze", etc., the way of asking is intuitive, it is unable to reflect the students" ability of summarizing and applying.

\subsection{The Content of Assessment Is Not Comprehensive}

The examination content focus on theoretical knowledge from textbooks or teaching material in most colleges and universities, the assessment of practical ability is ignored, the weight can reflect the ability and quality is lighter. Even the objective questions, the standard for evaluation are mostly set up according to the text and explanation by teachers at ordinary times, the space is little for students to express freely and broaden thinking, for this reason most students spend more time on the text and ignore the practice, they regard knowledge as important and ignore the ability, they satisfy with passing the test, consequently, it greatly weakened the basic requirements to measure the quality of the students in an all-round way.

\subsection{The System of Examination and Management Is Rigid}

At present, the educational administration department is responsible for the assessment of colleges and universities, as the main body of the teaching system, the department and the teaching \& research section is ignored in the appraisal function. For the professional education the teaching tasks are same time the educational administration department is limited by other tasks, so it is difficult for them to complete the assessment with a high standard and high quality, on the other hand the related security system such as the system of evaluation and selective examination as the main part in the professional education is not perfect, it is fail to give full play to the test in the feedback function of education. This is largely affected the teaching effectiveness and quality examination.

\section{The Design of $1+X$ Evaluation Mode}

For the assessment reform, the key is to build the scientific and reasonable mode of test. By investigating we make sure $1+\mathrm{X}$ evaluation mode is a feasible and effective reform, it includes the basic content and organization and the way of assessment, as well as form a relatively complete examination system.

\subsection{The Basic Content of $1+X$ Assessment}

Aiming at the shortcoming of the current appraisal model, such as paying attention to the theory and ignoring the practice, the examination mode being single, the evaluation mode being short of science. Knowledge and ability consist of the main content, the test stands out the ability of learning, innovating, working. "1" emphasizing on the knowledge of subject in the test, by the traditional comparative test, stressing on the theoretical knowledge. " $\mathrm{X}$ " focusing on the ability in the test, according to the object, content, purpose of the examination, the units given lessons apply on putting into practice the brand new form of the test comprehensively to test the operational ability, practical ability, research and innovational and working ability, etc. The results of " 1 " and " $\mathrm{X}$ " are comprehensively evaluating by certain proportion.

\subsection{The Organization and Complement of $1+X$ Evaluation Mode}

" 1 " is the theoretical knowledge of evaluation, when the course is end, taking the closed examination or forming 
examination paper by database at random. The closed examination can be propositioned by the teaching \& research section, and the test can be organized by the college. If the courses have the database, the test paper can be made up by the propositional plan, and the grade given by the system according to the key and standard for evaluation. " $X$ " is the part of ability test, including the content, way, operation, scenarios, intercourse, academic papers and other ways, or choosing one or more inspection way, the grades are judged by the assessment team, In the process of assessment the unites, enterprises, and other unit can be invited to conduct joint inspection, in order to evaluate the working ability of students comprehensively.

\subsection{The Way to Evaluate Comprehensively in the $1+\mathrm{X}$ Appraisal Model}

Comprehensive evaluation is the evaluation of students comprehensive quality, including the moral, profession, culture and physical and mental evaluation. $1+\mathrm{X}$ assessment is directing at the profession and knowledge of students, focuses on the operational ability, analyzed ability and professional ability. The evaluation of moral quality can be organized by democratic appraisal according to the performance of students at usual. Physical quality is the evaluation of the student's body and psychological quality. It can be comprehensively evaluated by the physical activity at ordinary times, psychological test and social contact and the other hands. The final grades include morality, works, culture, mind and body, at the same time the four aspects are weighted average by certain radio.

\section{The Measures to Carry out 1 + X Examination Mode Reform}

Implementation of the $1+\mathrm{X}$ examination mode reform is a complicated system engineering. It needs the corresponding measures to complete. In summary it should strengthen the in-depth study in the pattern, form, evaluation of the test, the three aspects should connect with each other in order to operate conveniently, furthermore, ensure that $1+\mathrm{X}$ examination mode reform can put into effect successfully, and get twice the result with half the effort.

\subsection{Strengthening the Research on the Way of Examination, Innovating the Mode of Assessment}

It is important to study further the way of examination when carry out the $1+\mathrm{X}$ evaluation mode form, and build up the scientific assessment mode fitting to the professional ability. Professional education is the training for the demand of working ability. The examination not only includes the theoretical knowledge, more highlights the ability and quality assessment, then can attain the effect of testing comprehensively. therefore, it must demonstrate the knowledge and ability of students, and build up the suitable examination according to the requirement of quality, give correctly play to the evaluation, it is important for testing the effect of training.

\subsection{Strengthening the Research of Examination Form, Establishing the Way of Multivariate Test}

It needs to strengthen the research of examination form, establish a flexible way of diversified examination when carrying out the $1+\mathrm{X}$ examination mode reform. We discuss the following aspects in view of the current problems in the test. One is the research of examination form. In the reform of test, it is necessary for the different forms according to the characteristics of course and the students, such as the oral reply, papers, operation and so on, in order to strengthen the openness. Second is the research of type, in the reform of examination, reasonable type can examine the knowledge and ability of students comprehensively.

\subsection{Strengthening the Research of Evaluation System and Improving the Evaluation System Perfectly}

Implementation of $1+\mathrm{X}$ examination mode reform not only needs strengthen the research of evaluation system, but also should build the scientific and perfect working ability quality. For students attending the job training, the quality-oriented education in working ability should include four parts, such as moral, profession, culture, mind and body, and so on. A single test fails to measure the four parts. Consequently, the evaluation index system conforming to the students in professional education should be studied carefully, and apply it to various 
kinds of examination, test and evaluation, it is important for guiding students to develop in an all-around way. In formulating the examination system, it is necessary to take the students' learning attitude into consideration, at the same time, it should adhere to the principle qualitatively and quantitatively, all indexes are quantitative should be avoided, in order to make sure the results of assessment are rational, scientific and fair.

\section{Conclusion}

In order to carry out the reform of $1+\mathrm{X}$ evaluation mode successfully, it is important to consider everything comprehensively, for example, the relationship between knowledge, ability and quality, at the same time it must do well in the single quality and comprehensive quality. On the one hand, it can ensure the students' personality development; on the other hand it can promote the students to develop comprehensively.

\section{References}

Dai, S.-H. (2009). The Reform of Course on the Professional Education. Beijing: Tsinghua University Press.

Han, S.-J. (2011). The Exploration of Evaluation Mode in the High Professional University. Education and Profession, No. 29, 166-167.

Li, X.-Q., \& Shu, H. (2011). The Exploration and Practice of Examination Model Reformed by Stratified Teaching in Higher Vocational Mathematics Curriculum. Journal of Chifeng University, 9, 252-253.

Niu, W.-X. (2000). Quality Education Calls for the Examination Reform. Education of Naval Academies, 3, 73-74.

Wu, Y., \& Wu, Y.-M. (2011). On Problems and Solutions of the Appraisal System for the University Talents. Journal of Jinhua Professional and Technology University, 11, 8-10.

Zhao, J.-Z. (2010). The Research on the Present Situation of the Examination Reform in Higher Vocational Colleges. Chinese Examination, 7, 40-44. 
Scientific Research Publishing (SCIRP) is one of the largest Open Access journal publishers. It is currently publishing more than 200 open access, online, peer-reviewed journals covering a wide range of academic disciplines. SCIRP serves the worldwide academic communities and contributes to the progress and application of science with its publication.

Other selected journals from SCIRP are listed as below. Submit your manuscript to us via either submit@scirp.org or Online Submission Portal.
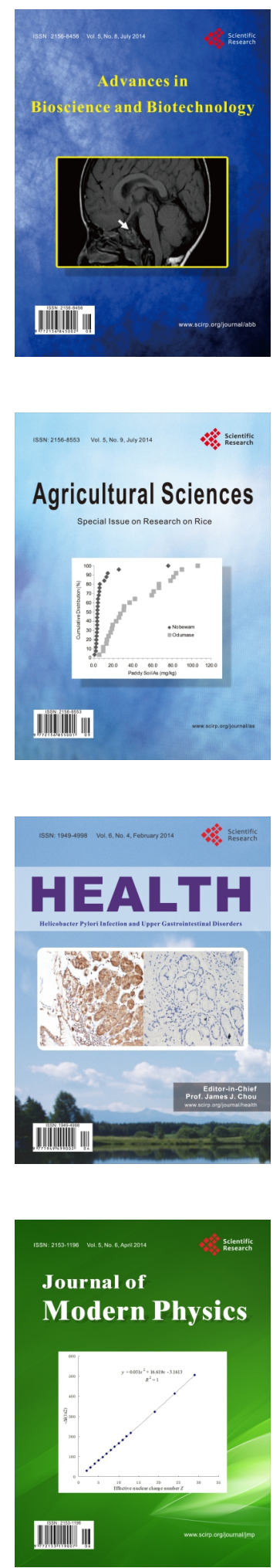
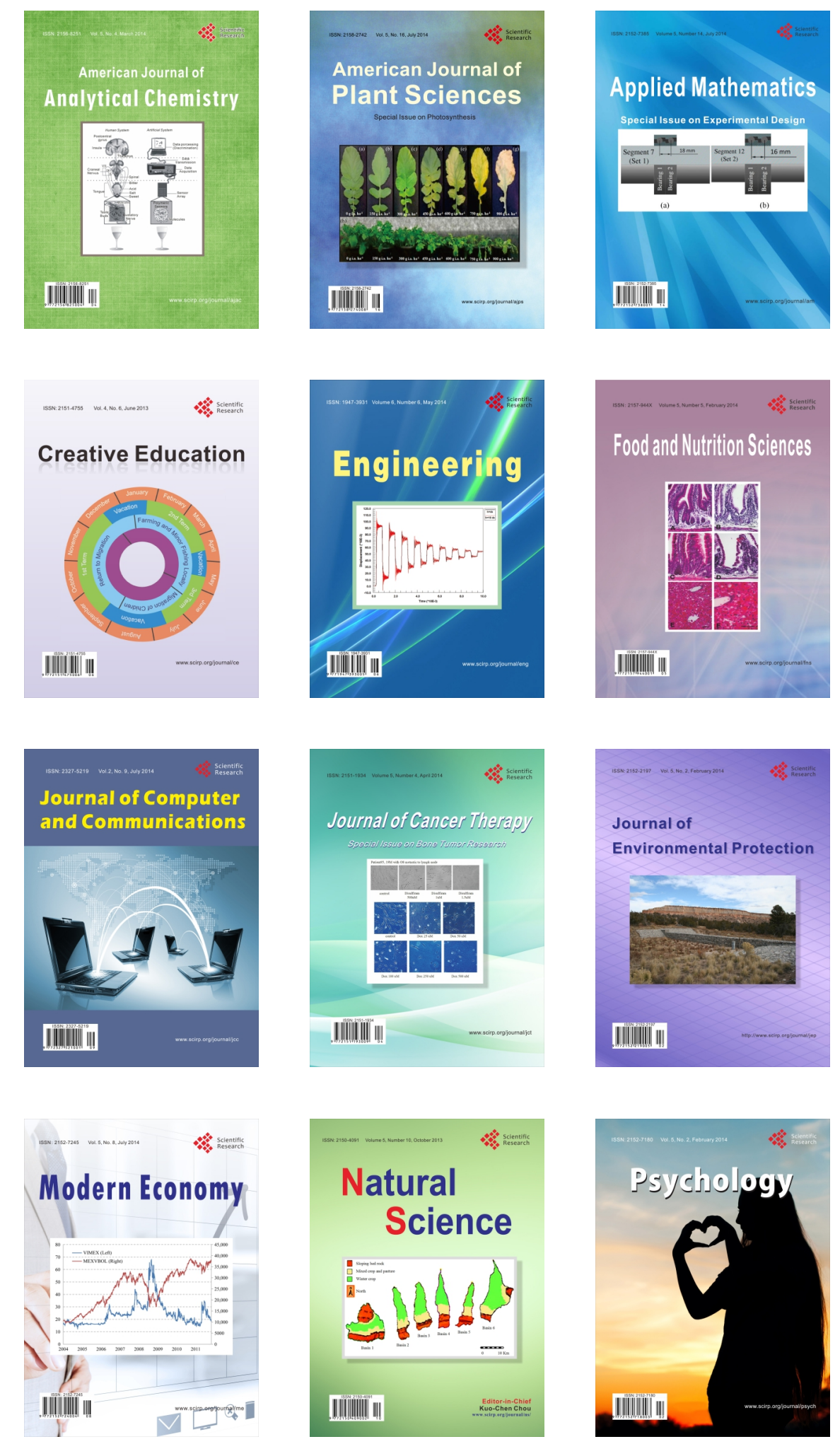